\title{
Interface Realisms
}

The interface as aesthetic form

\author{
Søren Pold, http://www.bro-pold.dk/ \\ Ass. Prof. \\ Institute of Aesthetic Disciplines/Multimedia \\ University of Aarhus, Denmark $^{1}$
}

Up until now, digital art forms have largely been understood within the traditional art forms as electronic literature, net.art or electronic, techno music. Sometimes interesting discussions have arisen concerning the very ontology of digital art and questions such as whether net.art should be seen within the tradition of the visual arts or as a form of literature connecting it to the different traditions and questions regulating these art forms. ${ }^{2}$ While it is not my intent to disconnect digital art from historical traditions within traditional art forms, or to argue the irrelevance of the traditional art forms, I will in the following establish the interface as an aesthetic and critical framework around digital art.

The interface is the basic aesthetic form of digital art. Just as literature has predominantly taken place in and around books, and painting has explored the canvas, the interface is now a central aesthetic form conveying digital information of all kinds. This circumstance is simultaneously trivial, provocative and far-reaching - trivial because the production, reproduction, distribution and reception of digital art increasingly take place at an interface, ${ }^{3}$ provocative because it means that we should start seeing the interface as an aesthetic form in itself that offers a new way to understand digital art in its various guises, rather than merely a functional tool for making art (and doing other things); and, finally, it is far-reaching in providing us with the possibility of discussing 


\section{Manuscript, forthcoming in Postmodern Culture, Winther 2005. Please do not} redistribute.

contemporary reality and culture as an interface culture, as well as with the potential for digital art to explore what this means.

In what follows I shall begin pursuing these three lines in order to outline the interface as an aesthetic form. I shall start out by taking a brief look at the explorations of the interface undertaken in the fields of engineering and computer science in order to sketch out the traditions that dominate the design, functionality and cultural conceptions of the interface. In these traditions, realism is the keyword - not a realism found in aesthetic tradition, but a realism that stems from the pragmatic urge in engineering to deal with reality. I shall then confront this realism with aesthetic realism and the question of how digital artworks can be seen as a reflection on and reaction to this. Finally, I shall analyze a computer game (Max Payne), a net.art game modification (Jodi's SOD) and a software artwork (Auto-Illustrator) in order to discuss how they engage with the interface and what they make us see through and in it.

\section{The engineered image}

The graphical user interface (GUI) as we know it does not stem from an aesthetic tradition, but from an engineering tradition that has paradoxically tried to get rid of it, and until recently it has largely been understood in technical terms and developed in engineering laboratories. Important starting points were Ivan Sutherland's first graphical, interactive interface in Sketchpad (1963), Douglas Engelbart's Online System NLS (1968), which introduced information windows and direct manipulation via a mouse, and Alan Kay's development of the desktop metaphor and overlapping windows. ${ }^{4}$

In continuation of this engineering tradition the Human-Computer Interaction (HCI) research tradition emerged, which from the beginning aimed at increasing the "user-friendliness" and "transparency" of the interface and during the years has involved cognitive sciences, psychology, ethnographic fieldwork, participatory design, etc. One of the leading usability experts, Don Norman, writes the following in an article from 1990 titled "Why Interfaces Don't Work":

\footnotetext{
"The real problem with the interface is that it is an interface. Interfaces get in the way. I don't want to focus my energies on an interface. I want to focus on the job." And later: "An interface is an obstacle: it stands between a person and the system being used. [...] If I were to have my way, we would not see computer interfaces. In fact, we would not see computers: both the interface and the
} 


\section{Manuscript, forthcoming in Postmodern Culture, Winther 2005. Please do not}

redistribute.

computer would be invisible, subservient to the task the person was attempting to accomplish." $(209,219) \cdot{ }^{5}$

Replacing the interface, its expression and materiality in favour of functionality and usability has been of key importance within large parts of interface design and the accompanying academic discipline, HCI. Also in the broader cultural and social understanding of the computer, the tendency has been to understand the interface as transparent, preferably invisible, for the benefit of a mimetic model of the task one is working on. ${ }^{6}$ Interfaces should be intuitive and user friendly, should not "get in the way" or otherwise be evident or disturbing. This has led to development of the ideals of direct manipulation and the WYSIWYG (What You See Is What You Get) slogan for the Graphic User Interface (GUI), which became a leading sales argument for the Apple Macintosh from the mid-1980s. ${ }^{7}$ Perhaps the apotheosis of the transparent, invisible interface was Virtual Reality, which was widely believed to be the next interface paradigm from the mid-1980s to about the mid-1990s, when it gradually lost some steam. In the dominant perceptions of VR, the interface should be all encompassing and threedimensional, and the user should be surrounded by an immersive, total simulation. The interface would thus simultaneously disappear and become totalized. Currently, some believe that the future lies in pervasive computing and augmented reality, which is sometimes envisioned as a new version of the all-encompassing interface, while others have more modest beliefs.

\section{The realisms of the interface}

If the computer and the interface really had become truly invisible and transparent, computers would mingle almost seamlessly with the world as we know it - perhaps making it a bit 'smarter'. If this were true, digital technologies would probably not have any paradigmatic effect on culture and aesthetics since they would not make a marked difference, but of course reality has proven different, and we can now begin to acknowledge the massive cultural and aesthetic impact of digital technologies. In fact, it is my view that we can acknowledge this impact through digital art: how the interface changes what and how we see, how we experience and interact with reality and how this reality is reconfigured through the computer. Digital art in general shows us the role of the interface and the significance of the interface as an aesthetic, cultural and ideological object. Through reflexive and self-reflexive moments and strategies it foregrounds the 


\section{Manuscript, forthcoming in Postmodern Culture, Winther 2005. Please do not redistribute.}

interface in ways that traditional software normally does not. Consequently, digital art becomes an important witness to the changes the computer has brought and is still bringing to our societies, and digital art and aesthetics can also help enlighten the HCI research field with regards to cultural and aesthetic aspects. ${ }^{8}$

Already in 1997, Steven Johnson wrote a book called Interface Culture, in which he argued that the interface was the most important cultural form of our time, comparing it to postmodern cultural and aesthetic forms. Steven Johnson argues that we live in an interface culture, and that the shift from analogue to digital is "as much cultural and imaginative as it is technological and economic" (Johnson, 40). Lev Manovich (2001) has with his notion of the cultural interface further developed the cultural aspect, and artists, conferences, journals and designers have started taking up the concept of the interface and its cultural, aesthetic impact. ${ }^{9}$

What is an interface? The purpose of the interface is to represent the data, the dataflow and data structures of the computer to the human senses, while simultaneously setting up a frame for human input and interaction, and translating this back into the machine. Interfaces have many different manifestations and the interface is generally a dynamic form, a dynamic representation of the changing states of the data or software and of the user's interaction. Consequently, the interface is not a static, material object. Still it is materialized, visualized, and has the effect of a (dynamic) representational form. In this way, the arts function as a correction to the transparency ideal. Instead of focussing only on functionality and effects, digital art explores the current materiality and cultural results of the interface's representational effects. What are the representational languages of the interface, how does it work as text, image, sound, space and so forth, and what are the cultural effects, for instance, of the way it reconfigures the visual, textual or auditory? How does the interface reconfigure aesthetics and what does it do to representation, communication and, in continuation of this, the social and the political? These are all important questions regarding the aesthetics of the interface, but one should still not leave out the engineering roots of the interface, both in order to understand the full context and consequences of interface art and in order to see how digital art can feed back into its development. Therefore, postmodern and poststructuralist aesthetic theories should be balanced with the pragmatic realism of the engineers.

Interfaces are often implemented as window screens with keyboards and mice, the so-called WIMP interfaces (Window Icons Menus and Pointers), but other 


\section{Manuscript, forthcoming in Postmodern Culture, Winther 2005. Please do not redistribute.}

information displays and interaction devices are of course possible, from different interface designs to different input and output devices such as VR helmets and gloves, the various ambient displays and devices imagined within the domains of hybrid architecture, ubiquitous computing, augmented reality, pervasive computing and so on. The interface aims to give us insight into the machine and its dataflow and can thus be understood as a sort of realistic representation along the lines of the engineering tradition outlined above. It is most likely even the predominant form of realism in contemporary culture, both conceptually and stylistically; however, it is far from naïve realism. As Johnson writes:

\footnotetext{
"Put simply, the importance of interface design revolves around this apparent paradox: we live in a society that is increasingly shaped by events in cyberspace, and yet cyberspace remains, for all practical purposes, invisible, outside our perceptual grasp. Our only access to this parallel universe of zeros and ones runs through the conduit of the computer interface, which means that the most dynamic and innovative region of the modern world reveals itself to us only through the anonymous middlemen of interface design." (Johnson, 19).
}

This suggests a different understanding of the interface's realism than what is suggested by the transparency ideal and WYSIWYG. The interface is, as suggested by the quotation from Johnson, rooted in an active and dialectical relationship between reality and representation, the interface entering in front of - or perhaps more correctly instead of an increasingly invisible reality. ${ }^{10}$ Here we are closer to aesthetic realism - for instance, literary realism, which is not based on a naïve mimetic faith in the possibility of reproducing or depicting reality, but rather on a loss of immediate reality with the rise of urbanity, capitalism and modern media. Consequently, aesthetic realism in broad terms represents an active and constructive reaction to a heterogeneous, mediated, complex and symbolic reality. ${ }^{11}$

The interface aims to visualise invisible data. It is a new kind of image originating in an engineering tradition and can be understood as an extension of instruments like radar and scientific visualisations, which do not represent any analogue image of reality but sheer data. ${ }^{12}$ As formulated by Scott deLahunta, the interface is "more information than likeness; more measurement than representation." ${ }^{13}$ Consequently, realism is the dominant representational mode of the interface, even though it is a complex, informational and postmodern realism. ${ }^{14}$ In the following, I shall point out three rather different kinds of interface realism: illusionistic, media and functional realism. Of course, they are not mutually exclusive but are often mixed and 
Manuscript, forthcoming in Postmodern Culture, Winther 2005. Please do not redistribute.

combined - for example, as layers in the same interface. The realist agenda is set by the engineering tradition, and I will discuss how the three art works reflect this realism in three different perspectives. Consequently, I shall ague for a realist perspective on the art works, even though at least some of them might not look like traditional realism to the immediate eye.

\section{Illusionistic realism: First-Person Shooter}

Illusionistic realism drives the computer game industry and further drives the demand for still better resolution and graphics, more realistic scenery and better sound cards. In addition, the interfaces of computer games have developed towards a real-time generated $3 \mathrm{D}$ space, which is often seen from the perspective of the player and/or his avatar in the game. From Wolfenstein 3D (1992) and Doom (1993) the First-Person Shooter (FPS) has evolved as a dominating genre that has developed into the Third-Person Shooter sub-genre, in which the avatar becomes a character with a personal story and a fictionalized perspective.

The FPS perspective is in certain respects the apotheosis of the illusionistic interface. It derives from simulations and Virtual Reality in its enactment of "the subjective, point-of-view aesthetics that our culture has come to associate with new media in general" (Bolter \& Grusin, 77). As this quote suggests, the FPS perspective not only inherits the visual perspective, but also the ideologies that came with Virtual Reality, which can be described as a super-individualized and apparently omnipotent linear perspective - a visualization of the bourgeois free individual. In the words of Bolter and Grusin, the representation strives towards immediacy. ${ }^{15}$

Traditionally, the FPS perspective is determined by the shooting range of impressive, phallic guns. The player perceives and interacts through oversized guns, and criticizing the gendered implications of this would definitely be a truism. Indeed, the FPS genre can be said to overstate and in some cases even invert the ideal of the free bourgeois individual, one striking example of which is the grid-locked noir detective of the computer game Max Payne (2001) - a game marketed as "realism to the max". ${ }^{16}$ However, also the illusionism of the game is gradually reversed and turns out to offer an experience of mediated perception.

The game's narration starts at the very ending, and the player has to struggle for hours to reconstruct the plot in order to return successfully to this ending. 


\section{Manuscript, forthcoming in Postmodern Culture, Winther 2005. Please do not redistribute.}

As is typical of the genre, the main character and player-avatar, Max Payne, is caught in a stratified maze controlled by drug lords and corrupt police, and only a combination of clever tactics and desperate shooting will get him out, after which he is trapped in the next level. ${ }^{17}$ The player is caught in a space and a plot that is clearly controlled by others - the mobsters and the urban spaces on the level of the plot and the cybernetic game engine on the structural level. In this sense the cyber-noir narrative of Max Payne is a reversal of the ideals of interactivity as a way of setting the user free and giving him control.

A closer narrational analysis of Max Payne supports this view, which I shall elaborate below in order to analyze how the experience of the interface is also a narrative experience. Max Payne seems almost like a comment to the heated discussion around the functioning of narrative in computer games. ${ }^{18}$ As mentioned, the game starts at the ending, and the player has to move back in narrated time in order to reconstruct the plot. ${ }^{19}$ The plot follows classical Aristotelian or Hollywood standards with three acts, a beginning, middle and end, a point of no return and increasing narrative tension. The story - and the game play - is at first sight all about exploring, enacting and reconstructing a plot that is static, in the past tense, linear and written beforehand. Already through this immediate first level of the narrative it becomes clear that the game does not aim to fulfill the ambitions of interactive narratives. In any case, the player does not interactively control the plot, rather the game only lets the user investigate and carry out an already firmly established plot. Just as the game inverts the ideologies of mastery and the sovereign individual inherent in the first-person perspective, it also runs counter to the libertarian notions of interactivity as empowering the user. Rather than controlling the story, the player is trapped by the plot.

The narrative serves more or less as a frame or motivation for the game play, but this is not all it does. Already in the third chapter of part one, a second metanarrative layer is introduced. As mentioned above, it is clear that we are playing a part in a well-known story. We know the ending and we are also quickly introduced to the usual clichés of Hollywood narration: the sudden destruction of the family idyll, the strong narrative conflict - even the weather is extremely horrible in order to emphasize the sinister setting. In this sense we are less primarily engaged in the narrative; instead it designates the narrative as a cliché. All the signs of Hollywood narrative in an extreme, clichéd, noir version get thicker and thicker until they more or less get in the way, in the sense that they point towards narrative structure in general rather than support the 


\section{Manuscript, forthcoming in Postmodern Culture, Winther 2005. Please do not redistribute.}

particular narrative. In chapter three we are told that we are now "past the point of no return", and the construction of the narrative is consequently laid out in such an explicit way that the game, as mentioned above, easily could be interpreted as a self-conscious intervention in the ongoing debate about the roles of narrative in computer games. Narrative becomes an effect that the game self-consciously alludes to and puts on but does not fulfil in the deep Aristotelian way imagined by the proponents of interactive narrative. ${ }^{20}$ Instead narrative is only a surface or skin that does not attempt to become hegemonic, covering all aspects of the game, but like postmodern novels and cinema it alludes to narrative, quotes it, and deconstructs it, without fully enacting it. If narrative is a grand master scheme that secures coherence, Max Payne at once enacts and dismantles it.

Hence, the game engages a postmodern meta-narrative that is explicitly conscious of its noir genre, even pointing out intertextual references: chapter three is called "Playing it Bogart" and other later references include "Noir York City" and Max Payne describing himself as someone who "had taken on the role of the mythic detective, Bogart as Marlowe, or as Sam Spade going after the Maltese Falcon..." Indeed, the main character, Max Payne, also slowly reveals himself as just a narrational character - a role or a function in the narrative - which is highlighted by the symbolism of his name. Already in the beginning we are told to go back "to the night the pain started", and in chapter three Max Payne enters a hotel "playing it Bogart", while the "cheap mobster punks" in there make fun of his name ("it's the pain in the butt" and "pain to the max!").

Through the overt character of the noir detective Max Payne we enter into what can be seen as the third level of the narrative, which is the mediated story or the story of mediated perception and recognition. Here we are closer to the story level, the game play and how it mediates between the plot and the telling of the story. First we recognize the role that media such as newspapers, radio and television play in creating a bridge between the plot and the story. Through various news clips we discover that the police are chasing Max Payne. Second, it is obvious that Max Payne is often hindered in seeing and sensing by darkness, fire, dream sequences or drugs, which by exaggerating the normal navigational difficulties point out the mediated perception of the FPS.

In this story of mediated perception, Max Payne is our senses, and he can endure a maximum amount of pain (if we just remember to grab some pain killers on the way), though his pain is only mediated by a red bar in the interface and narrated by his voice and through his frequent deaths - the ultimate failure of the story, after which the 
Manuscript, forthcoming in Postmodern Culture, Winther 2005. Please do not redistribute.

player has to reload a saved game and start the scene again. This mediation of Payne's pain demonstrates the very perspective of the game as an FPS game - how the perspective is at once mediated and illusionistic. Especially the beginning of the third act, where Max Payne is drugged, shows this, since the perspective is strangely widened and the movements are slowed down - defamiliarizing effects which emphasize and therefore demonstrate the machinery of the normal game perspective or interface. ${ }^{21}$

The interface thus supports and becomes an important part of the story of mediated perception. The apparent immediacy of the illusionistic FPS interface is gradually but effectively turned into a hypermediated experience through the difficulties of navigating and seeing in the space of the game. This is especially evident in the sequences where seeing, hearing and navigating are hindered by darkness, fire or by Max Payne being drugged or in other ways numbed. This hypermediated experience, which is emphasized by the above-mentioned remediations, is explicitly addressed as a topic in the first chapter of part three. In a graphic novel sequence in the drugged beginning of the third act, Max Payne first realizes that he is a character in a graphic novel, and in a strange defamiliarizing repetition that he is also nothing but an avatar in a computer game: "Weapon statistics hanging in the air, glimpsed out of the corner of my eye. Endless repetition of the act of shooting, time slowing down to show off my moves. The paranoid feel of someone controlling my every step. I was in a computer game." 
Manuscript, forthcoming in Postmodern Culture, Winther 2005. Please do not redistribute.

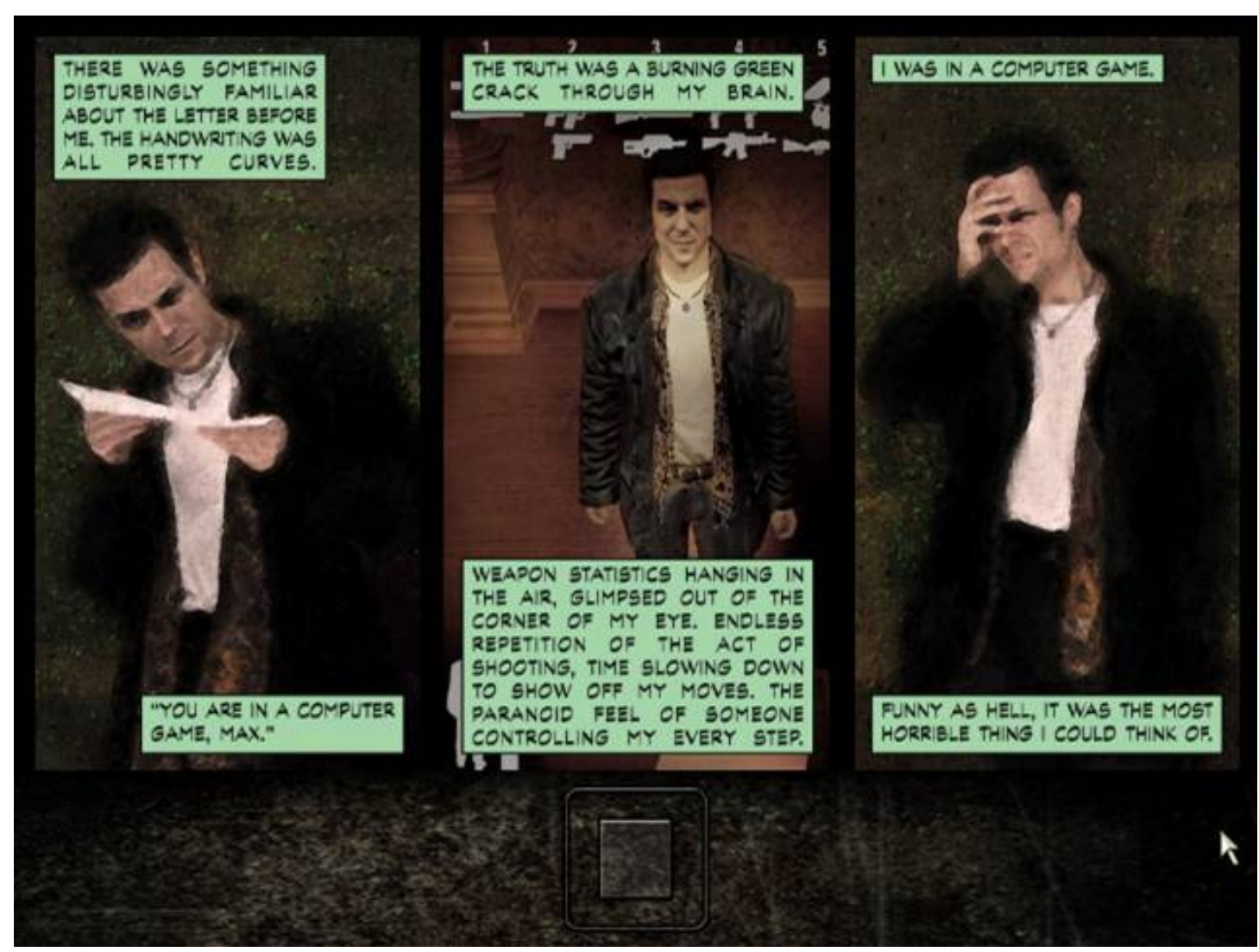

[insert ill. 1 approximately here. Caption: Max Payne deconstructing the illusionism]

Consequently, the game performs a deconstruction of its illusionism. The apparent immediacy of the perception is turned into a hypermediated experience of the interface. Seeing, hearing and even the tactile senses are explicitly mediated - one touches the narrative space through weaponry and is hurt through a red bar - and max pain is turned into pleasure. The illusionistic realism of the game Max Payne is on the one hand carried out as "realism to the max"; on the other hand, the game explicitly plays on the media of the computer, the interface, media in general and mediated perception. The game at once performs, explicitly demonstrates and consequently deconstructs illusionistic realism. Through the game the transparent interface is simultaneously enacted, reversed and subverted. As shown by the narrational analysis, already the first plot level of the narrative subverts the myths of interactivity, while interactive fiction and illusionism is critically inverted by the next levels. In this sense the game and its narrational aspects critically reflect upon important popular assumptions of the interface such as interactive control, interactive fiction or the myth of the user being in control of the narrative coherence, and interface illusionism.

This criticism is not made from a safe distance, but from within the medium and the discourse. As the noir genre in general it performs what the Los 
Manuscript, forthcoming in Postmodern Culture, Winther 2005. Please do not redistribute.

Angeles-based cultural historian Norman M. Klein calls (quoting Mike Davis) a

"transformational grammar", turning the utopian notions it enacts into their opposite (Klein, 80). In addition, it is no coincidence that Max Payne inherits a noir style, which already from its outset was a media hybrid. Already in the noir cinema and novels of Raymond Chandler, noir was clearly a media hybrid of filmed novels and cinematic literature often set in a thoroughly cinematographic Los Angeles. ${ }^{22}$ The realism of Max Payne is still largely illusionistic since it acts out a super-illusionistic FPS perspective inheriting characteristics from VR and connected utopias, but during the game the mediation and hypermediacy become apparent through a deconstruction of the naïve illusion or immediacy.

Consequently, it is more precise to categorize Max Payne as illusionistic media realism - realism that simultaneously engages in illusion and is a self-reflexive exploration of its own representational techniques and media. Max Payne is more than illusion. One gradually sees the media, techniques, aesthetics and genres of the game in a process whereby it, though still engaging in illusion, gradually reveals itself as a selfreflexive and genre-conscious art form.

\section{Media realism - murder in the museum}

The multimedia computer was introduced at the beginning of the 1990s as the result of an almost iconophilic belief in the power of 'natural', 'universal' and 'intuitive' images. The advent of net.art can be regarded as a counter reaction to the iconophilia of the computer industry - as some sort of digital iconoclasm. Jodi, one of the pioneering groups of net artists (recently the first net artists to be canonized by a retrospective gallery exhibition ${ }^{23}$ ) is constantly aiming at deconstructing the images on the screen through their works, showing the codes behind the screen and revealing the normally hidden flow of codes that the user interaction causes. In what often looks like beautiful crashes, they show the symbolic and coded flipside to the interface. ${ }^{24}$ 
Manuscript, forthcoming in Postmodern Culture, Winther 2005. Please do not redistribute.

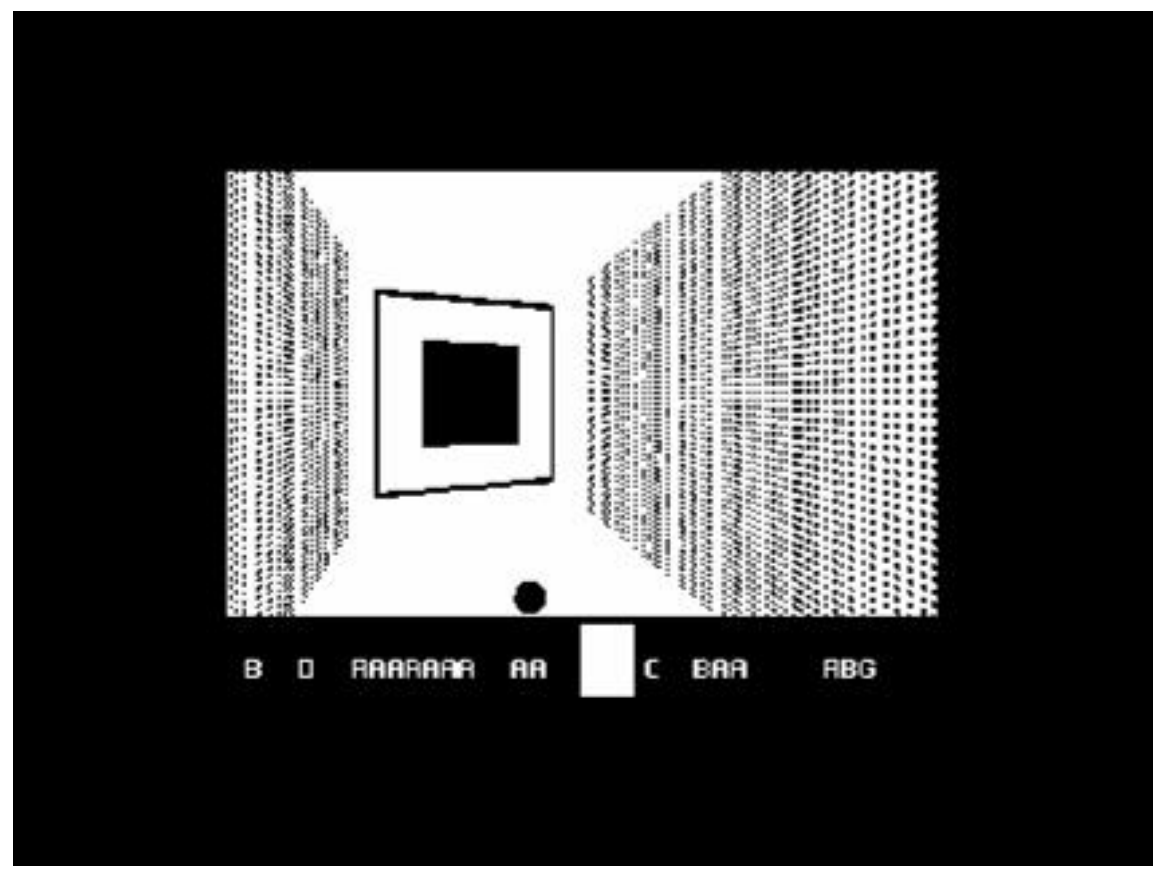

[Insert ill. 2 app. here. Caption: Jodi's Sod]

From around the year 2000 Jodi has made a series of game modifications.

If the mediated and hypermediated gradually comes into view through the illusionistic interface of Max Payne, Jodi's FPS game modifications directly focus on the mediation to the extent that it is sometimes hardly possible to see the game at all. In one of their first games, Sod, ${ }^{25}$ the usual dungeons from the FPS classic Wolfenstein and Doom are modified to abstract white rooms with geometric figures and patterns instead of Nazis and monsters. "Murder in the museum" is what one could call their modification of the classical FPS to the white cube of the museum (Sod is a modification of Wolfenstein 3D). The walls have been stripped of their textures, and what turns out to be doors between the various rooms looks like one of the major works of abstract art, Malévic's Black Square. The player is located in an abstract, suprematist, black and white art museum with a finger on the trigger. It is possible to navigate this abstract space, though this is made difficult by the fact that it impossible to see the walls; sometimes they are actually transparent. The basic characteristics from FPS are still intact - the player navigates spaces and attacks or is attacked by enemies (appearing as two triangles) - but the experience is rather different from more traditional games. Jodi has dropped the illusionistic texture, thereby underlining the fact that both space and interaction are based on abstract codes, algorithmic structures and cybernetic interaction - a fact that also experienced game players know and take advantage of when they, for example, in relation to Counterstrike talk about playing the game instead of the illusion. 
Manuscript, forthcoming in Postmodern Culture, Winther 2005. Please do not redistribute.

With Sod, the computer game is reduced to geometry and algorithms and can therefore be seen as a critical comment on the illusionism in traditional games. However, it can also be seen as a comment on the debate about computer games, which in many ways is a revival of the conservative resistance to comic strips, rock ' $n$ ' roll, youth culture and so forth. Sod is Wolfenstein stripped of its Nazi violence, turned into abstract art and placed in a 'safe' context: the art museum. It is the computer game as "Art" with a capital A and in quotation marks. In this way Sod mocks the art world and high art, and Jodi's ironic modification also pays homage to computer games and gaming culture. Jodi does not turn its back on popular game culture, but explores it, investigating its form and tactics for making game modifications; they do not stay in an autonomous art-related medium, but rather turn the aesthetics of the computer into art.

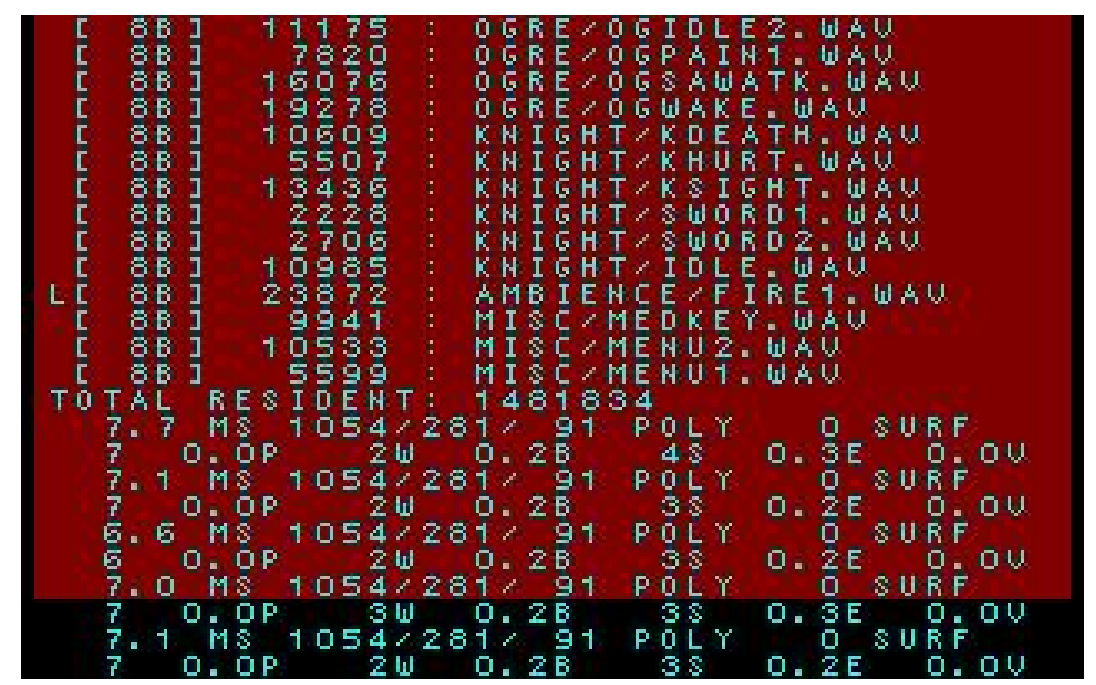

[insert ill. 3 app. here. Caption: Jodi's $A-X$ ]

After Sod Jodi has made Untitled Game, a series of abstract computer games made on the Quake game engine, another classical FPS. ${ }^{26}$ The series ranges from games taking place in an abstract system of co-ordinates, flickering moiré interfaces, glitch-like remixes of the original game, and games that simply print the code controlling the interface on the screen instead of executing it. All these games can be considered as a radical critique of the naïve illusionism that governs large parts of the computer graphics industry and computer games. But perhaps what is more interesting is how they demonstrate the elements of the interface, strip off the texture and show the abstract geometry of digital space - how they demonstrate the materiality and mediality of the interface. The players often lose their orientation, but in turn they are given a unique experience of an abstract, modern, informational and cybernetic space, an experience which in many ways gets closer to the computer and the functioning of the interface by 
Manuscript, forthcoming in Postmodern Culture, Winther 2005. Please do not redistribute.

creating a distance to the illusion. The games point towards a sort of computer game that goes beyond the illusionistic, uses the interface as an instrument and plays with its materiality. The interface, contrary to much HCI wisdom, does get in the way and become an obstacle - in fact, the interface is the experience and what you see is what you get!

Media realism in net.art is often dominated by formal investigations nevertheless it is still realism in the sense that it deals with perception and sensation at the interface, though from a starting point directly opposed to the illusionistic realism described above. Whereas illusionistic realism starts with our senses and with how sensation has been addressed in earlier media such as the cinema and then collides with the forms and potential of the interface, media realism starts with the media and then tries to show how it collides with our senses, knowledge, cultural forms and expectations.

\section{Functional realism - don't push this button}

Besides the visual dimensions of illusionary realism and media realism there is another more active dimension of realism that becomes especially important with the computer. ${ }^{27}$ Functional realism in HCI is related to regarding the computer and its software as a tool, as something "ready to hand." 28 This funtional perspective has produced much software, that we use everyday without thinking consciously about it. In general, usability engineering is about designing interfaces in ways so we can use them instead of focussing on them. With this functional realism we are perhaps closer to the engineering heart of HCI than the more cultural and entertainment-related illusionistic realism. Functional realism is about control and functionality rather than illusion and immersion.

Frieder Nake, the German computer scientist who is one of the pioneers of computer graphics, perceives the computer as an instrumental medium that we use instrumentally as a tool or an automaton while communicating with it as a medium (Nake). This constant shifting between the instrumental use and the communicational and representational functions of the medium is inherent to most computer applications - even computer games and net.art have a functional dimension related to navigation, interaction and functions such as "save", "open" or "print", while functional software tools also have representational dimensions, often as an intrinsic part of the very metaphor(s) behind the software design. 
Manuscript, forthcoming in Postmodern Culture, Winther 2005. Please do not redistribute.

It would be easy to dismiss the functional dimension of the computer as irrelevant to art and aesthetics, or perhaps as a naïve realistic belief in the power of representations - a belief that aesthetic theory routinely deconstructs. Still, this functional realism is part of the computer interface, of its conceptualization, its visual aesthetics and our understanding of it. Following Nake's concept of the instrumental medium, the computer is a new kind of machine that mediates the instrumental or functional and functionalizes the representational medium. This dual quality is, though difficult to understand from a postmodern aesthetic point of view, turned into a standard mode of expression - for example, in digital images on the web and in multimedia that besides their representational character are embedded with hidden buttons, objects and scripts.

The functional interface and the functions of software have been investigated in artrelated projects, especially in the emerging genre of software art. Digital artists have of course always used software, but in continuation of net.art's media-realistic investigation into the very medium of the networked computer, digital artists have started working with software as an artistic medium.

According to Florian Cramer, software as an art form has some roots in concept art and early experimental software development. In 1970 the art critic Jack Burnham curated an exhibition called "Software" that included both concept art and experimental software. Cramer claims that this was the first concept art show, but it also included a prototype of Ted Nelson's hypertext system, "Xanadu", apparently the first public demonstration of hypertext. Software art and concept art are both characterized by the artist primarily creating the frames for an artwork, the concept. However, in software art, the concept, such as programming, includes both notation and execution in other words, both the concept and its potential implementation. ${ }^{29}$

Besides its roots in concept art and literature, ${ }^{30}$ software art is a development of tendencies within net.art. From artistic web pages that were executed in ordinary browsers like Netscape and Internet Explorer, around 1997 net.artists started to include the software that showed the pages in their artistic work. Some net-artists started working with web browsers, an early and significant example being I/O/D's The Web Stalker, which has had several successors. ${ }^{31}$ Software art is already established through annual festivals like the Read_Me festival curated by Olga Goriunova and Alexei Shulgin. 
Manuscript, forthcoming in Postmodern Culture, Winther 2005. Please do not redistribute.

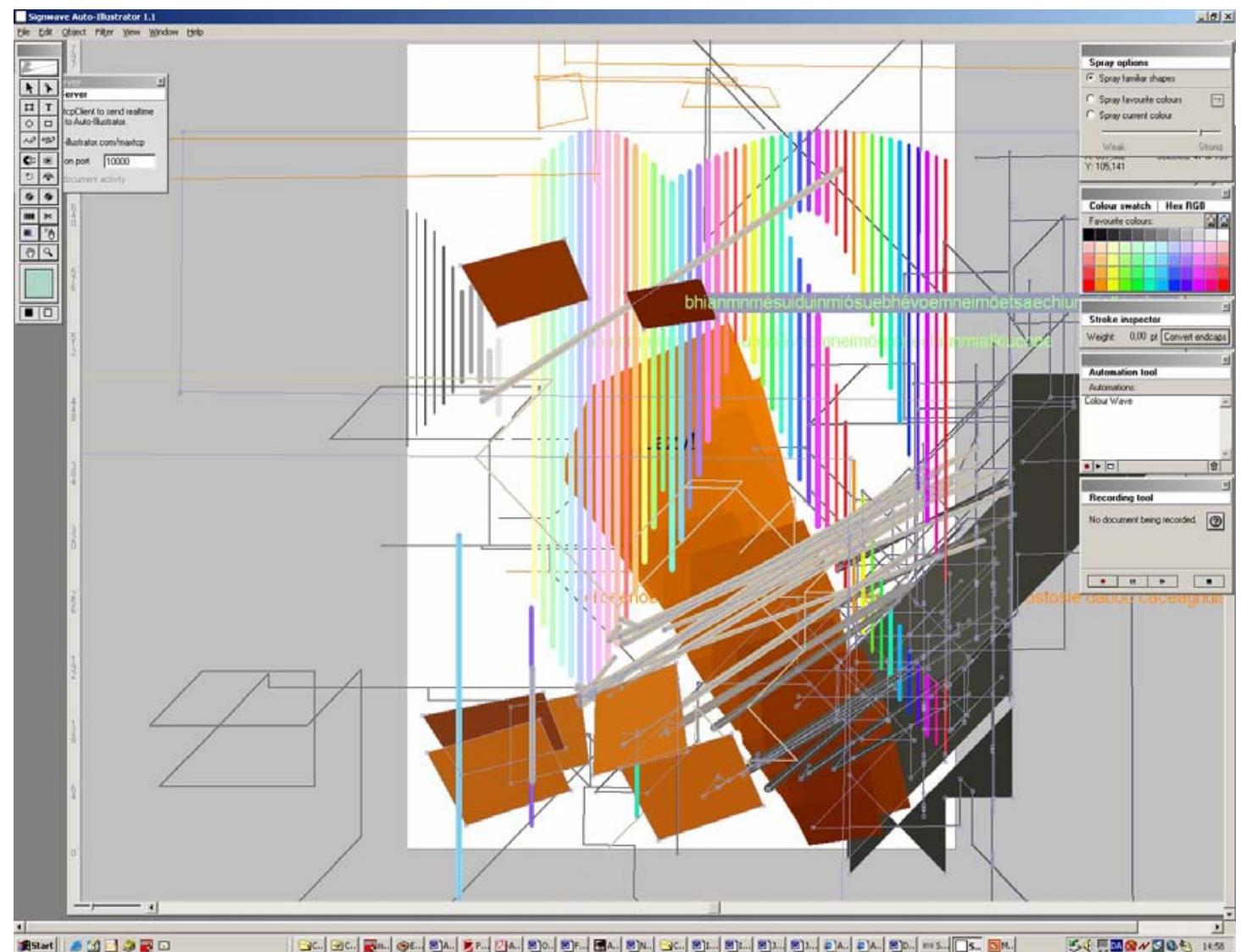

[insert ill. 4 app. here. Caption: Adrian Ward's Signwave Auto-Illustrator]

One of software-art's groundbreaking works is Adrian Ward's Auto-

Illustrator (2000-2003), ${ }^{32}$ an artwork that investigates how software as an apparently functional tool also serves as a representational structure that influences culture, aesthetics and art. Auto-Illustrator demonstrates how the instrumental is also mediated, according to Nake's understanding of the computer as an instrumental medium. It is a complete and full functional drawing programme that via generative algorithms draws autonomously through interaction with the user. In one feature, the user places a number of "bugs" on a drawing and adjusts their parameters while they draw autonomously.

Drawing circles, squares and lines also turns out to be an explicit act of co-operation with the software, which instead draws childish faces, childish houses, and twisted lines, respectively, according to adjustable parameters. Besides, the drawing can, as in traditional drawing software, be manipulated by a number of filters and plug-ins that unlike traditional software have their own, autonomous will. For example, some filters such as "generate instant results" or those called "nq297p" create objects according to quasi-random generative procedures. ${ }^{33}$

Auto-Illustrator is not radically different from ordinary software, since it uses the standard control interface of the modern graphical user interface (GUI). It started 
Manuscript, forthcoming in Postmodern Culture, Winther 2005. Please do not redistribute.

out as a parody on Adobe interfaces from Illustrator and Photoshop, and Adrian Ward explicitly criticizes the radically different interfaces so often seen in digital art works for being beside the point: "I want to express myself using the medium of consumer-based application software, which is why Auto-Illustrator doesn't have a radical interface" (Ward, 2002-2003, 118). Auto-Illustrator follows the standard user interface guidelines, and even its strangest functions appear as tools and filters, like those also found in more traditional software. In this way, Auto-Illustrator demonstrates an alternative to the way functionality is dressed up as a mere tool in ordinary software. Auto-Illustrator suggests that functionality includes all kinds of aesthetic and representational choices that are normally hidden under the tool metaphor, which thereby keeps the user unconscious of these choices. It demonstrates the representational character of the instrumental, and that the artist working with specific software has severely limited his potential for expression, but it also points out that main-stream software is limited in its potential for creativity because it has to stay within the range of the tool metaphor. Furthermore, this takes place within the well-known medium of the traditional GUI that Auto-Illustrator uses as an artistic medium - a strategy that makes its critical reflection on software culture and interface aesthetics more precise in relation to everyday interface culture than for example hi-tech VR phantasmagorias.

Auto-Illustrator paves the way for a discussion of how the tool and functionality work as representational and aesthetic structure, a discussion that potentially reconfigures the whole field around artist, tool and artwork. As Adrian Ward expresses it: "If a plug-in can be authored that reproduces that trendy graphical effect that everybody loves, how does this impact upon the role of the graphic designer, and thus how does one treat the software that produced the design? Who is the designer? The user, or the author of the code?" "34 $^{4}$

In this way, Auto-Illustrator performs a critique of the conception of ordinary software, questioning the implied perceptions in ordinary software of the user as the active artist/author and of the software itself as a passive tool. Taking a look at digital art, it becomes clear that specific software and software-hardware combinations play an enormous role for the works produced - imagine digital photography without Photoshop, electronic music without Steinberg's Cubase or the products of Roland, hyperfiction without Eastgate's Storyspace, or multimedia without Hypercard, Director or Flash. The software plays an important part by virtue of how it conceptualizes the user, the material user works with, and the way the software stages itself as a partner in the usage. ${ }^{35}$ 
Manuscript, forthcoming in Postmodern Culture, Winther 2005. Please do not redistribute.

The traditional conceptualizations of user, object and software are critically demonstrated and radically changed by Auto-Illustrator. The user is normally conceptualized as active and in-control, but could just as well - and perhaps often more in line with the actual truth - be conceptualized as re-active and partly controlled, as in many computer games, where the interface is more opaque and difficult to control. The material the user works with is most often metaphorized as something well-known and relatively stabile - for instance, paper, a photograph, a canvas - but could also be more dynamic, algorithmic, cybernetic and emergent, as in Auto-Illustrator or browser art such as The Web Stalker or Feed. And, finally, the software, which often stages itself as passive, supportive and neutral, could instead be active, interfering and creative such as AutoIllustrator, and perhaps in the end this is what qualifies it as an artwork.

Auto-Illustrator performs a criticism of traditional software - one could say that it foregrounds and liberates the creative potential of software and is therefore an example of a new, more active form of software for producing art that does not follow romantic ideals of the genius artist, but makes it clear that artist and software are a cybernetic entity. As a consequence of this, it also enacts a critique of the traditional transparent and functional interface, which it clearly imitates and uses as its artistic medium. Some functions turn out to be opaque, unpredictable and difficult to control, but the functional GUI itself can also be deconstructed or simply destructed: In the "preferences" palette it is possible to change the language from English to "Jodi" or "m9ndfzzzp", ${ }^{36}$ or one can find the very button that best expresses the intention of AutoIllustrator.

The "preferences" palette is perhaps the most sacred place on the interface (apart from the 'deep level' of code which is behind the interface and thus normally not visible). In the "preferences", "settings" or "control panels" it is possible to manipulate the very staging of the interface, its colours, language, interaction menus, file handling, warning messages and so on. It is here that one is allowed to personalize the software and change passwords, here that the author or producers of the software to some extent make the staging of the interface explicit. The preferences section is a small peephole into the backstage area, but it is also where the relations between author, software and user are defined, though of course within strict limits. It is not possible to change everything, and often one cannot find the setting that controls an annoying feature one wants to get rid of. 
Manuscript, forthcoming in Postmodern Culture, Winther 2005. Please do not redistribute.

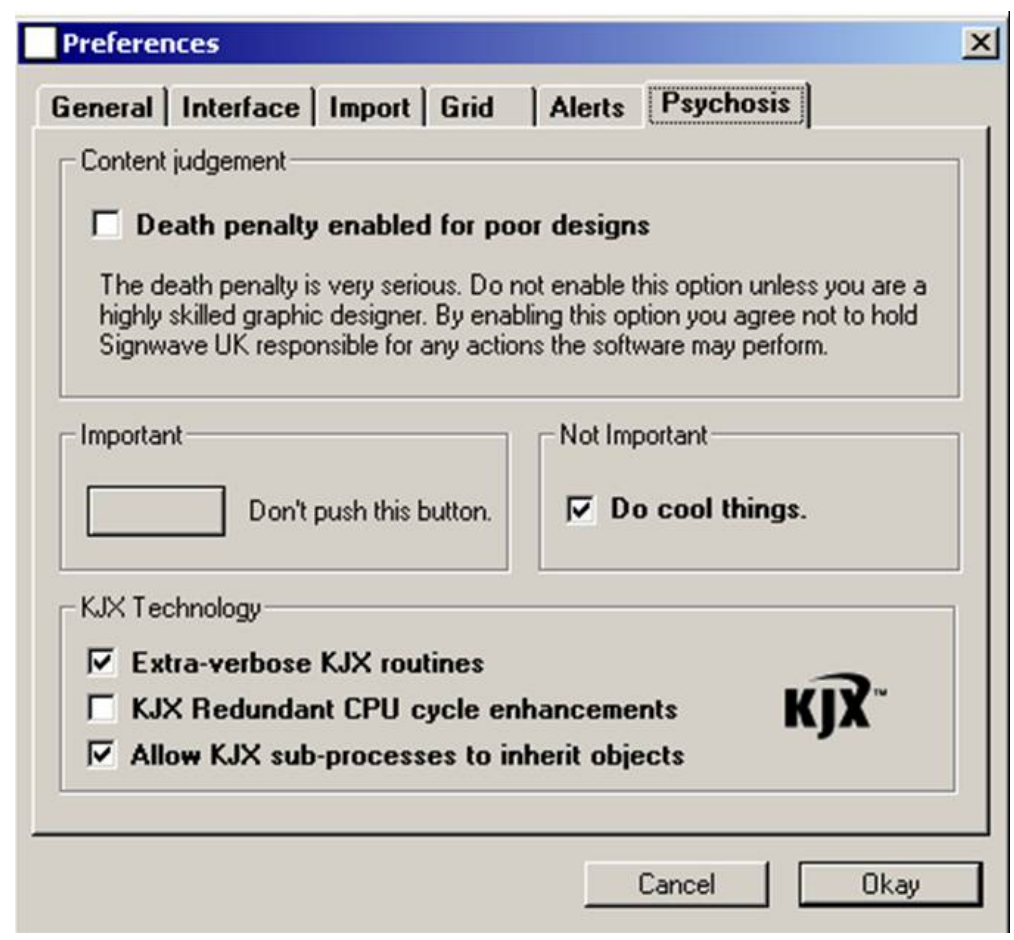

[insert ill. 5 app. here. Caption: Preferences palette in Adrian Ward's Signwave AutoIllustrator]

In Auto-Illustrator, apart from actually choosing "annoying mode" or choosing to "mess up palettes" in the "interface" section of the "preferences" palette, it is possible to enter the "psychosis" section, where the "Important - Don't push this button" button is located. Here Auto-Illustrator clearly and self-consciously addresses the very ontology of software interfaces. By choosing "Psychosis" the user is of course already well out of line, and, in fact, the "Don't push this button" button highlights the normally repressed schism between the functional-instrumental and the mediated in Nake's definition. What is often a repression of the representational and mediated nature in traditional software interfaces is turned into an expressive psychosis here.

Focussing on this button the schism of the instrumental medium becomes clear. A button indicates a functional control, by means of which something well defined and predictable will happen as an effect of the user pressing the button; the fact that it is often rendered in 3D simulates a physical, mechanical cause-and-effect relationship. Of course, we know that it is in fact a symbolic representation and as such a mediation of a functional expression, but we nevertheless see and interpret it as something that triggers a function - and for good reason indeed, since it is designed to perform in this way. It is a software simulation of a function, but normally this simulation does not point toward its representational character, but acts as if the function were natural or mechanical in a straight cause-and-effect relation. Yet it is everything but this: it is conventional, coded, 
Manuscript, forthcoming in Postmodern Culture, Winther 2005. Please do not redistribute.

arbitrary and representational, and as such also related to the cultural. Or perhaps the cultural, conventional and representational elements are disguised as pure technical functionality. However, as manufacturers of technological consumer goods from cars and hi-fi equipment to computer hardware and software know, buttons have aesthetic qualities and should respond to a desire to be pushed. This could be interpreted as a desire for control, but perhaps it is also and primarily a tactical desire. Buttons and knobs are supposed to feel good - one can even read car reviews that criticize the buttons and controls of a Korean car for their cheap 'plastic' feeling. In Auto-Illustrator this button's desire to be pushed is paradoxically heightened and pinpointed by the text "Don't push this button". One could say that by its apparent denial of functional purpose the button self-consciously tempts our desire for the functional experience of tactical control and mastery - a strong ingredient in the aesthetics of the functional interface, even when denied.

When the button is pushed, the functional realism is cancelled and the interface itself turned into something that resembles an opaque net.art work. Text in palettes is turned into gibberish code, windows are moving and sounds are beeping, and the clear distinction between the data and the programme, which is necessary in order to sustain the illusion of functional software, is cancelled. ${ }^{37}$ This button delimits a borderline between the functional interface and the modernist representational concept of aesthetics. Here one envisions new critical, functional art within the instrumental medium of the computer - not as an optimistic compromise but as a rupture between two clashing modes: the representational mode of art and the functional interface. When pushed the rupture is radicalized, the schism is turned into sheer psychosis, the functional into pure art. Consequently, one should not push this button, because it destroys the delicate balance between the functional and the representational in AutoIllustrator, between seeing its interface as a tool and as a 'pure' representational art form. ${ }^{38}$ When pushed, Auto-Illustrator turns into pure parody or negative criticism, but it is much more than this. As software art it both points out a new kind of software and a new kind of art. 
Manuscript, forthcoming in Postmodern Culture, Winther 2005. Please do not redistribute.

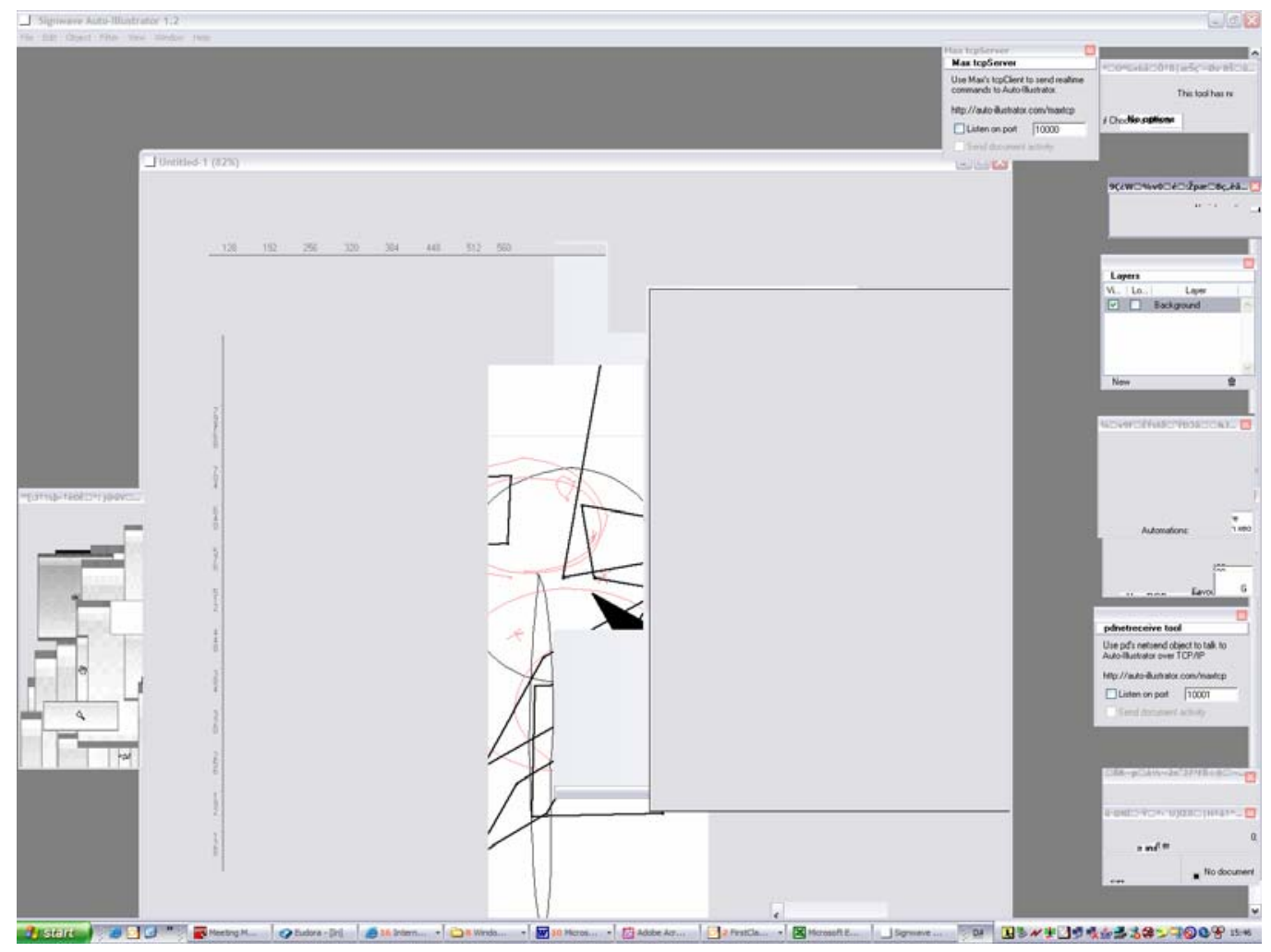

[insert ill. 6 app. here. Caption: Don't push this button is pushed. Adrian Ward's Signwave Auto-Illustrator]

Auto-Illustrator functions on three interconnected levels. It serves as an alternative to normal software, which emphasizes how functionality and tool metaphors often hide the aesthetic choices and representational effects. It presents a criticism of the roles outlined in traditional software - of who is the actor, what is acted upon and whether the software is transparent in this process. And, finally, it enacts the very interface as an artwork itself - an artistic interface that is itself an aesthetic experience. In these three steps, and within each of them, it indicates the schisms of the instrumental medium; how the mediation with all its cultural, aesthetical and ideological dimensions is most often black-boxed by the functionality, and how the instrumental medium opens up for functional aesthetics.

By these three steps it criticizes naïve conceptualizations of software as a tool, and even though large parts of the HCI community are aware that software is not always transparent, there is still too little awareness of what the cultural functioning of software is. What are the aesthetical, cultural and ideological ramifications of functional aesthetics? How does it influence our experience and perception, and what does it do to the arts? ${ }^{39}$ 
Manuscript, forthcoming in Postmodern Culture, Winther 2005. Please do not redistribute.

The very object of the artwork is once again questioned by such artistic experiments. How does the artwork actually work in a political and cultural economy? The myth of the autonomous work of art is increasingly difficult to sustain - a fact which also makes digital art, net.art and software art somewhat difficult to discuss and sell, though Auto-Illustrator has chosen to use the contested model of proprietary software, and sells licenses to the software. ${ }^{40}$ Functional realism as demonstrated by Auto-Illustrator critically highlights central issues in the GUI and in the computer as an instrumental medium. It is all about functional changes in the media, aesthetics and the arts - and about changes in the very concept of functionality itself.

\section{The realisms of the interface}

In this article, I have maintained that the interface should be regarded as a cultural and aesthetic form with its own art - digital art that goes under the names of net.art, software art, computer games - but I could have included (and shall include in further work) electronic literature that deals with relations between the code and the interface or between the work, the text and the network - a good example of the former would be www.0100101110101101.org, of the latter Christophe Bruno's www.iterature.com. In addition, questions about the cultural aspects of the interface are also raised in contemporary techno-culture and techno music, notably in genres like laptop music. For example, the musician Markus Popp (Oval) argues that we should understand music as software, in terms of the software processes used to produce it. ${ }^{41}$

Furthermore, I have discussed contemporary realism, since realism is an objective raised by the industry, by HCI research and by broad cultural conceptions of the computer. I have pointed out that there is more than one realism, that realism is not only naïve illusionism and nor can it be reduced to What You See Is What You Get, but the question of realism can be raised from different perspectives. As I have argued, one actually sees different things through these different perspectives, although they are clearly related and cannot be fully isolated. Furthermore, my three categories of realism aim beyond the safe borders of the autonomous artwork: illusionistic realism aims beyond pure representation towards immersive simulation, media realism beyond the visual surface towards the imperceptible and unreadable code, and functional realism 


\section{Manuscript, forthcoming in Postmodern Culture, Winther 2005. Please do not redistribute.}

beyond the artwork as self-contained and disinterested towards a functional aesthetics of the instrumental medium.

Realism is ultimately about seeing and reaching reality - a reality that is not something alien 'out there' but that consists of media and to a certain extent is constructed with media. This construction of reality through media is both conceptual as when media functions as models of understanding reality, and directly physical as when media becomes embedded in the infrastructure of postmodern reality. ${ }^{42}$ In its most stringent form, realism puts the very concepts of art and the real at risk simultaneously, so it is encouraging that some of the heated discussions of computer games, net.art and software art have concerned how - or if - one should look at this as art. What are the boundaries of net.art and software art? This discussion was highlighted by the fact that the Open Source operating system Linux was awarded Ars Electronica's Golden Nica in the category of net art in $1999 .{ }^{43}$ But when dealing with the interface from a realistic perspective, perhaps the most pressing questions are where the interface is, what it looks like, and how and what it makes us see. Is the interface a moving target we are hunting down in dark corridors of first-person shooters? Is it the opaque digital materiality of Jodi's game modifications? Or is it hidden in the playful interaction of Auto-Illustrator?

Part of the answer is that the interface is a continually developing form for various functional and artistic practices - a moving target that artists will keep following and exploring, just as artists have explored the canvas or writers the codex and produced important insights without ever exhausting the basic form. By pursuing this moving target, the materiality of the interface is gradually rendered manifest, visible, readable, audible, navigable and so forth. The most significant contribution of interface aesthetics to the development of the interface is probably making sure that it does not become "invisible", transparent, "subservient to the task", as claimed by Don Norman in 1990 (see above), but that it does "get in the way" and is explored as a form, a language, an aesthetics. This is not in opposition to the functional usability dimensions of the interface, but it might help to develop an understanding of the cultural dynamics, an understanding that is important when interfaces are increasingly mingling with the cultural dimensions of everyday life. Moreover, by nature the interface is a dynamic form that can appear in various disguises, as I have also argued by means of my three forms of realism. Interfaces are made for interaction and thus keep adjusting to accommodate the actual user and use. In this sense we can never fully grasp the interface as a form, but are compelled to pursue its various and ever-changing appearances. 
Manuscript, forthcoming in Postmodern Culture, Winther 2005. Please do not redistribute.

\section{Works Cited}

Albert, Saul: "Useless Utilities", Presented at the Netuser conference in Sofia, 2001, http://twenteenthcentury.com/saul/useless.htm - reprinted in Auto-Illustrator Users Guide (Ward, 2002-2003)

Baumgärtel, Tilman, BüroFriedrich (ed.): Install.exe - Jodi, Christoph Merian Verlag, Basel, 2002

Bolter, Jay David \& Richard Grusin: Remediation - Understanding New Media, The MIT Press: Cambridge \& London, 1999

Cramer, Florian: "Concepts, Notations, Software, Art", http://userpage.fuberlin.de/ $\sim$ cantsin/homepage/writings/software art/concept notations//concepts not ations software art.html reprinted in Auto-Illustrator Users Guide (Ward, 2002-2003

Fuller, Matthew: "A Means of Mutation" in Josephine Bosma, Pauline van Mourik Broekman et. al. (ed.): Readme! Filtered by Nettime, Autonomedia: New York, 1999, 37-45

Jameson, Fredric: "Postmodernism, or The Cultural Logic of Late Capitalism", New Left Review, 146, July-August 1984, 53-93

Klein, Norman M.: The History of Forgetting - Los Angeles and the Erasure of Memory, London, New York: Verso, 1997.

Latour Bruno \& Emilie Hermant: Paris ville invisible, Paris: La Découverte, 1998Manovich, Lev: The Language of New Media, MIT-Press, Cambridge (Mass.) \& London (England), 2001.

Max Payne, Remedy/3DRealms, Finland, 2001

Nake, Frieder: "Der Computer als Automat, Werkzeug und Medium und unser Verhältnis zu ihm", in H. BUDDEMEIER (Hrsg.): Menschenbild und Computer. Selbstverständnis und Selbstbehauptung des Menschen im Zeitalter der Rechner. Bremen: Universität Bremen, Medienkritische Reihe 3, 2000. 73-90.

Norman, Don: "Why Interfaces Don't Work" in Laurel, Brenda (ed.): The Art of Human-

Computer Interface Design, Addison-Wesley, 1990,

Ward, Adrian (ed.): Auto-Illustrator Users Guide, Liquid Press: England, 2002-2003, included as PDF with Auto-Illustrator 1.2 
Manuscript, forthcoming in Postmodern Culture, Winther 2005. Please do not redistribute.

Ward, Adrian /Signwave UK, 2003: Auto-Illustrator 1.2, Shareware with free trial version, http://www.auto-illustrator.com/

Wardrip-Fruin, Noah and Nick Montfort (ed.): The New Media Reader, MIT-Press, Cambridge, Massachusetts \& London, England, 2003

\section{Notes:}

${ }^{1}$ This article is the product of discussions and research carried out with Lars Kiel Bertelsen and Olav W. Bertelsen and has benefited from discussions at the occasions where it has been presented. Stacey M. Cozart has helped with linguistic corrections. Thanks also for extremely valuable comments and corrections from reviewers at PMC, which have helped improve this article.

${ }^{2}$ In visual arts questions concerning the art institution and its connections to museology are important, while from a literary perspective questions concerning writing versus code and the functions of authors and readers are important. For the museology perspective, see the curator Steve Dietz's influential paper "Curating (on) the Web", presented at "Museums and the Web", 1998, http://www.archimuse.com/mw98/papers/dietz/dietz_curatingtheweb.html. For the literary perspective, see Florian Cramer, "Free software as collaborative text" and "Software art" available from http://userpage.fu-berlin.de/ cantsin/homepage/. I have explored the literary perspective in several Danish articles and in the English article "Writing the Scripted Spaces - Understanding writing in a digital context" available at http://imv.au.dk/ pold/publikat/scripted.pdf. Also within the field of computer games, heated discussions have also arisen around the relevance of a narratological approach versus an emerging ludological approach to computer games, the latter aiming at establishing the computer game as an art form of its own. I will return briefly to this discussion below.

${ }^{3}$ Of course there are many combinations of analogue and digital techniques, where parts of the work from its production, storage, distribution to modes of reception are still taking analogue forms even though other parts have been digitized. Furthermore, and perhaps more important, differences exist between how digital techniques have influenced the ontology and cultural economy of art works, even within a particular art form. Consider for example the differences between commercial pop/rock and techno music: the digital has only slowly led to substantial changes in most mainstream musical forms, whereas in techno and dj-culture the very ontology of the musical work is totally changed.

${ }^{4}$ In addition, the development of hypertext and hypermedia should be mentioned, notably the work of Vannevar Bush and Ted Nelson. See Noah Wardrip-Fruin and Nick Montfort (ed.), 2003, which collects many of the key historical texts.

${ }^{5}$ Iben Bredahl Madsen has used this quotation in her interesting attempt to consider the interface as an art form in her unpublished thesis Interfacet som kunstform (The interface as an art form), Multimedia Studies, University of Aarhus, 2002.

${ }^{6}$ See, for instance, Brenda Laurel, "Interface as Mimesis", in User-Centered System Design: New Perspectives on Human-Computer Interaction in D. A. Norman, \& S. Draper (ed.), Hillsdale, NJ: Lawrence Erlbaum Associates, 1986.

${ }^{7}$ See, for instance, Macintosh Human Interface Guidelines, chapter 1, on Direct Manipulation, WYSIWYG and metaphors (http://developer.apple.com/techpubs/mac/HIGuidelines/HIGuidelines15.html, Apple Computer, 1992); a new version for Aqua is found here: http://developer.apple.com/techpubs/macosx/Essentials/AquaHIGuidelines/ (08/06/2004). See also Schneidermann, 485-498, in Wardrip-Fruin \& Montfort (ed.), 2003.

${ }^{8}$ See e.g. Olav W. Bertelsen \& Søren Pold: "Criticism as an Approach to Interface Aesthetics" in NordiCHI proceedings, ACM Press 2004 (available through ACM digital library: http://doi.acm.org/10.1145/1028014.1028018

${ }^{9}$ Current examples are Switch, 18 ("Interface: Software as Cultural Production"). http://switch.sjsu.edu/nextswitch/switch_engine/front/front.php?cat=44 (09/06/2004)

${ }^{10}$ For a book that theorizes and documents how modern urban reality becomes increasingly invisible though continuously visualised in numerous locations and for various uses, see Latour \& Hermant.

${ }^{11}$ See, for instance, my article on the realism of Honoré de Balzac: "Panoramic Realism - An early and illustrative passage from urban space to media space in Honoré de Balzac's Parisian novels, Ferragus and Le Père Goriot", Nineteenth Century French Studies, vol. 29, no 1-2, 2000-2001, 47-63. Also 

redistribute.

Steven Johnson compares the interface as a cognitive map to "the great metropolitan narratives of the nineteenth-century novel" (Johnson, 18), though he mainly compares with Dickens.

${ }^{12}$ Cf. Manovich, 2003 and James Elkins: The Domain of Images, Cornell University Press: Ithaca and London, 1999.

${ }^{13}$ Lecture, Aarhus University, 1999.

${ }^{14}$ As mentioned, Steven Johnson is referring to the interface as a postmodern media form which inherits postmodern characteristics such as intertextuality, eclecticism, fragmentation and so forth, but the interface is also variously opposed to general notions of the postmodern. At least it suggests a strong technological, functional and instrumental dimension of the general postmodern culture. Still, it is interesting to re-read one of the defining articles of the postmodern, Fredric Jameson's

"Postmodernism of the Cultural Logic of Late Capitalism" in the light of the interface. Jameson hesitatingly illustrated the postmodern by "the distorting and fragmenting reflexions of one enormous glass surface to the other" (Jameson, 79) with explicit reference to the dominant role of computers and reproduction in postmodernity. The very same year that Jameson published his article (1984), Apple released its first Mac OS. Perhaps this 'convergence of contemporary critical theory and technology' to repeat the subtitle of George P. Landow's book Hypertext (The Johns Hopkins University Press: Baltimore, London, 1992) - offers the possibility to update and reconfigure of our notion of the postmodern.

${ }^{15}$ The dichotomy of immediacy and hypermediacy was set up and developed by Bolter and Grusin (1999). See 78-84 for a summary of the criticism of linear perspective in the tradition deriving from Panofsky.

${ }^{16}$ Max Payne was a huge success for the game development company, Remedy, based in Espoo, Finland. A sequel, Max Payne 2: The Fall of Max Payne, has been released in 2003.

${ }^{17}$ On tactical versus strategic ways of being in space, see Michel de Certeau: L'invention du quotidien 1. arts de faire (Gallimard 1990), especially XLIV ff. and $139 \mathrm{ff}$.

${ }^{18}$ See, for instance, Espen Aarseth: "Beyond the Frontier: Quest Games as Post-Narrative Discourse in Marie-Laure Ryan (ed.): Narrative Across Media, University of Nebraska Press (in Press), Jesper Juul: "Games Telling Stories? A brief note on games and narratives" in Game Studies, Vol. 1, 1, http://www.gamestudies.org/0101/juul-gts/ and Marie-Laure Ryan: Beyond Myth and Metaphor - The Case of Narrative in Digital Media" in Game Studies, Vol. 1, 1, http://www.gamestudies.org/0101/ryan/. Aarseth and Juul are leading opponents of the general academic trend of discussing games as narratives. Instead they emphasize the ludological ontology of games as something different from narrative, pointing to the importance of game-play, choice or ergodics and quests. While they definitely have a point in criticizing narrative hegemony as it is carried out, for instance, in the ideal of 'interactive fiction/story' and in many narratological game analyses, Ryan puts forth a more balanced (though also critical) version of narrative traits in digital media.

${ }^{19}$ The game is very explicit about this construction. The internal first-person narrator, Max Payne, explicitly states that "this is how it ended", and later he says, "To make any kind of sense of it I need to go back three years... Back to when the pain started." In my analysis I use the classical narratological distinction between plot and story (fabula and sjuzet).

${ }^{20}$ For example, Janet Murray: Hamlet on the Holodeck: The Future of Narrative in Cyberspace, MITPress, Cambridge, Massachusetts \& London, England, 1998.

${ }^{21}$ In addition, the game interface itself remediates other media to a large extent, and it is thus a perfect example of Lev Manovich's cultural interface category (see Manovich, 62-115): The plot is largely told through a photo realistic graphic novel complete with frames and text bubbles, and, as already mentioned, media serve to bridge the plot and the story. In addition, the game play is, as in many other computer games, interrupted by cinematic sequences using montage and spectacular camera movements, but also the game play itself is inherently cinematic in nature. Basically one sees the scenery through a camera behind and above the avatar, but there are also cinematic effects like a special slow-motion effect that can be enabled by the player, special effects when major crooks die and so on. Especially the "bullet-time" and "shoot-dodging" slow-motion effects are important for the player's tactics.

22 This is especially explicit in Chandler's The Little Sister from 1949 (New York: Vintage Books, 1988).

${ }^{23}$ An exhibition complete with a printed catalogue, in which Florian Cramer argues that: "If the contemporary art system were not fixated on displays - whether of opulent visuals or of political correctness - and on material objects to be sold, Jodi might be recognized as the most important artists of our time" (Baumgärtel \& BüroFriedrich (ed.)). 

redistribute. ${ }^{24}$ See, for example, the net.art works at http://404.jodi.org and http://oss.jodi.org, especially the
executable files that can be downloaded.
${ }^{25}$ Sod is available from http://sod.jodi.org.
${ }^{26}$ On the culture of making new levels, versions or modifications of an original game engine made
available by the game producers as a way of prolonging the life of a game, see the articles by Laura
Trippi and Erkki Huhtamo in Switch, 12 http://switch.sjsu.edu.
${ }^{27}$ Although it is not entirely new to claim a connection between representation and outward action in
realism and realistic theories such as speech-act theory and some aspects of dialectic materialism and so on.

${ }^{28}$ Heidegger distinguished between objects that are "ready to hand" and "present at hand", the former functioning seamlessly as tools (like a hammer) withdrawn into the activities in which one is engaged a distinction that has played an important role in HCI through Winograd and Flores' introduction in 1986 (cf. Paul Dourish: "Seeking a Foundation for Context-Aware Computing", http://www.dourish.com/embodied/essay.pdf (08/06/2004).

${ }^{29}$ Florian Cramer: "Concepts, Notations, Software, Art", http://userpage.fuberlin.de/ cantsin/homepage/writings/software_art/concept_notations//concepts_notations_software_ar t.html. The "Software" exhibition is documented with a reprint of the original catalogue in WardripFruin \& Montfort, 247-257.

${ }^{30}$ Cramer follows Henry Flynt in arguing that "concept art is a kind of art of which the material is language", and consequently that "software can be seen and read as literature" (Cramer).

${ }^{31}$ The Web Stalker can be downloaded from http://bak.spc.org/iod/. Other examples of browser art works are Mark Napier's Feed, Riot and Shredder (http://potatoland.org), and Maciej Wisniewski's Netomat (http://www.netomat.net/).

${ }^{32}$ Auto-Illustrator won the Transmediale 2001 price for Artistic Software and received an honorary mention at Ars Electronica in 2001. At the time of writing, the current version is 1.2 (Windows).

${ }^{33}$ Filters work through plug-ins that can be written and installed independently by the user or by a third-party producer.

${ }^{34}$ In "About Auto-Illustrator" in the documentation that comes with Auto-Illustrator 1.2. - For example, in Adobe Photoshop there are filters that more or less automatically create painterly effects or glass mosaics from a given image. Auto-Illustrator also demonstratively criticizes the pointlessness of many of the automated effects, a good example is the mocking, "stupid and pointless" filter in AutoIllustrator, which in fact does nothing at all and takes a long time doing it.

${ }^{35}$ See Saul Albert, who discusses the author function in Auto-Illustrator. He also discusses how traditional net.art intervenes between media producers and media consumers, while software art intervenes between software producers and media producers, thus higher up in the chain of production: "[T] $]$ he most influential position is clearly that of the software programmer, and the most obvious point for intervention is there, between the software producer and the media producer" (Albert, no page numbers).

${ }^{36}$ With "Jodi", Auto-Illustrator refers to the above-mentioned net.art group Jodi, and with "m9ndfzzzp" to the work of Netochka Nezvanova, which is a pseudonym for the artist behind works such as m9ndfukc.com, antiorp, EUsocial, and integer (Albert, 2001). In this way Auto-Illustrator pays respect to other net.art and software artists. However, this ability to change interface languages is discontinued in version 1.2.

${ }^{37}$ Other net.art works that reflect this aesthetics are works by Jodi, especially the OSS series of software that can be downloaded from oss.jodi.org.

${ }^{38}$ See also Albert's re-phrasing of Mathew Fuller's "not-just-art" concept, a concept Fuller developed for I/O/D's Web Stalker, and that Albert argues is more fitting to Auto-Illustrator. Fuller writes about Web Stalker as not-just-art in the sense that "it can only come into occurrence by being not just itself. It has to used." (Fuller, 43).

${ }^{39}$ When my five-year-old son sees an image on a computer screen he clicks on it like a maniac in order to enter or execute it. Consequently, by default he sees digital images as interfaces with hidden links and functionality besides seeing them as representations. His interpretation is directed towards the double-click.

${ }^{40}$ Even here it uses the medium of consumer-based application software, as pointed out by Adrian Ward, and not a radical alternative such as the open source model, though parts of Auto-Illustrator such as the plug-ins are in fact quite open and invite co-authorship.

${ }^{41}$ Interview with Markus Popp/Oval: "Music As Software" http://www.sospubs.co.uk/sos/oct02/articles/oval.asp 
Manuscript, forthcoming in Postmodern Culture, Winther 2005. Please do not redistribute.

\footnotetext{
${ }^{42}$ The idea of embedded computers and media is currently discussed within the research fields of pervasive computing, augmented reality, mobile handheld devices, etc. However, that our urban environment is media saturated is not linked exclusively to future technologies, see e.g. Latour \& Hermant.

${ }^{43}$ Among others, the net.artist and software art curator Alexei Shulgin has argued against seeing Linux as art, claiming that it is functional software while net.art is non-functional, an argument Florian Cramer rightly rejects as "late-romanticist" (Florian Cramer: "Free Software as Collaborative Text", available from http://userpage.fu-berlin.de/ cantsin/homepage/ (08/06/2004). See also the discussion after the prize was awarded on the nettime list under the thread: "<nettime> Linux wins Prix Ars due to MICROSOFT INTERVENTION" (http://amsterdam.nettime.org/Lists-Archives/nettime-l9909/threads.html\#00039 (08/06/2004)). The pressing question seems to be whether art can embrace the functional dimensions of software or whether art has to be dysfunctional in certain ways to maintain a critical distance.
} 